\title{
Promoting uptake and use of conservation science in South Africa by government
}

\author{
Nikki Funke* and Shanna Nienaber \\ Council for Scientific and Industrial Research, PO Box 395, Pretoria 0001, South Africa
}

\begin{abstract}
This paper aims to analyse how to encourage science uptake, here defined as the uptake and use of scientific research products (including journal articles, scientific reports, tools, expert knowledge, etc.), in the South African context. While science uptake into implementation is a very case- and context-specific process, the authors propose that a general framework for analysis of the policy-making context in South Africa needs to be considered when analysing how to promote science uptake in specific cases. In this paper, the National Freshwater Ecosystem Priority Areas (NFEPA) project is used as an example to illustrate how to apply this framework and how science projects in South Africa can be better positioned for impact and use. The paper starts by introducing the framework for conceptualising the complex set of dynamic processes and actors that can be involved in science uptake by government in South Africa, i.e., the policy-making context. From this theoretical platform the authors analyse to what extent the NFEPA project will be able to support more effective implementation of existing environmental and water legislation. This is done by exploring the challenges that hinder the uptake of science in government departments and then offering recommendations on how to address these.
\end{abstract}

Keywords: Science uptake, implementation, scientific research products, conservation science, South Africa

\section{Introduction}

Science is a valuable input into public policy, and specifically the ongoing process of policy implementation. Policy implementation is the process by which recommendations that are developed in the initiation and formulation of policy are incorporated into practice by administration agencies (Heywood, 2002), known as government departments in South Africa. Scientists can influence decisions that support policy implementation by making researched recommendations about the best possible solutions for complex implementation-related challenges and by developing tools to support policy implementation (Mubyasi and Gonzalez-Block, 2005; Watson, 2005; Shisana and Louw, 2006; Shung-King, 2006; Campbell et al., 2007; McNie, 2007; Nienaber et al., 2010; Strydom et al., 2010). However, despite extensive international literature that exists on the science-policy interface and the issue of science uptake into policy implementation, this process is still not happening to the extent that it should (Hanney et al., 2003; Bowen and Zwi, 2005).

In the conservation sector in South Africa, specifically, an acknowledged 'knowing-doing' gap exists between conservation science and implementation (Pierce et al., 2005; Knight et al., 2008; Boreux et al., 2009; Shackleton et al., 2009; Arlettaz et al., 2010). Implementation is for the purposes of this paper defined as government departments' responsibility for the implementation of water and environmental policy, including its monitoring, evaluation and enforcement. One of the reasons for this 'knowing-doing' gap is that many scientists have a limited understanding of the complex nature of the policy-making

\footnotetext{
* To whom all correspondence should be addressed.

+27 12841 2024; fax: +27 128413954 ;

e-mail: nfunke@csir.co.za

Received 22 February 2011; accepted in revised form 14 December 2011.
}

context within which science exists and interacts (Van Kerkhoff and Lebel, 2006; Nienaber et al., 2010), and perhaps for that reason do not plan for implementation (Knight et al., 2007), nor engage in ongoing social learning processes with decisionmakers (Shackleton et al., 2009).

There is an increasing realisation that the implementation crisis in the conservation sector needs to be addressed, and a growing body of literature has developed around this need. There is a need to manage, through negotiation, the boundaries between the producers of knowledge (researchers) and the executors of action (policy-makers) (Van Kerkhoff and Lebel, 2006). It is recommended that researchers and policymakers should understand and take into account into each other's motivations and reward systems (Gibbons et al., 2008). Researchers also need to understand and target the world of institutions, policies and politics (Pierce et al., 2005), as well as the processes of decision-making, behaviour change and value transfer (Reyers et al., 2010). Lessons can also be learned from other sectors, such as medicine and public health, and an evidence-based framework with the necessary infrastructure to support decision-making by managers can be adopted (Pullin et al., 2004).

In addition, it is important to build and maintain relationships between researchers and key stakeholders through meetings, discussions, workshops, databases, forums, etc., and to actively and effectively disseminate information to specific audiences based on the perceived demands of these audiences (Van Kerkhoff and Lebel, 2006; Gibbons et al., 2008; Pohl, 2008).

Other recommendations focus on planning for implementation through suggestions around the design of conservation planning process, assembling a combination of relevant skills of the conservation assessment teams, collaboration with stakeholders and public participation, and interpretation and mainstreaming of biodiversity concerns and values, as well as products (e.g. maps) into sectors such as agriculture, forestry, 


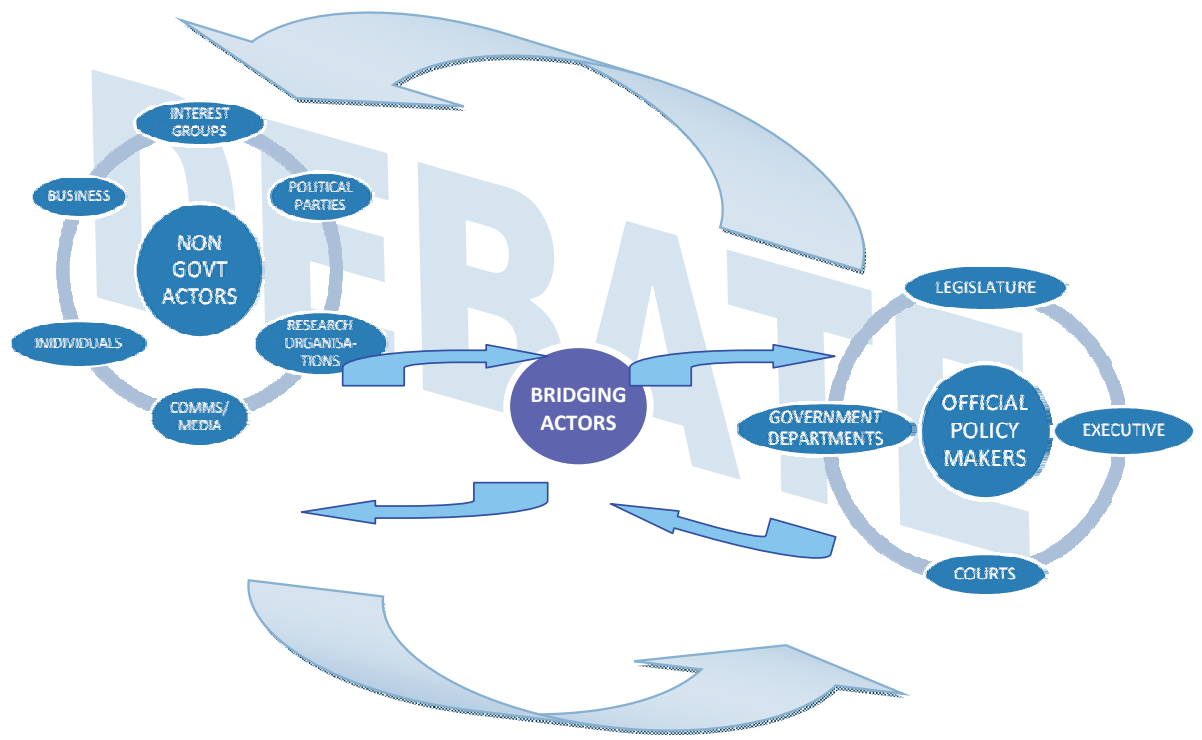

Figure 1

This diagram

illustrates the diverse spectrum of actors who can form coalitions to 'push' for specific policy preferences. These policy debates and resultant coalitions occur amongst official policy-makers, who are mandated to make and implement policy, and non-government actors, who influence policy (from Nienaber et al., 2010)

mining and land-use planning (Pierce et al., 2005; Knight et al., 2006; Cowling et al., 2008). Social learning institutions have also been identified as crucial to the successful implementation of conservation planning processes. In addition to conservation planners these should include diverse interest groups such as rural landowners, politicians and government employees (Knight et al., 2006, Van Kerkhoff and Lebel, 2006; Shackleton et al., 2009). In the same vein as social learning, there is a need for the co-production of knowledge between experts and users (Roux et al., 2006) or members of different cultures, the bureaucratic, academic, economic and civic policy culture each with their different reference points, through a process of interaction (Roux et al., 2006; Pohl, 2008). This means that science needs to move beyond bridging different disciplines to solve conservation-related problems and instead needs to become a social process that aims to resolve such problems through the participation and mutual learning of stakeholders (Reyers et al., 2010).

This paper contributes to literature around the relationship between the producers of science and the users of science in government departments, by analysing how to encourage science uptake into decision-making, monitoring and evaluation, and existing processes or the development of new ones. One of the challenges when making general recommendations about how to improve science uptake into implementation is that in reality this is a very case- and context-specific process. Nonetheless, the authors propose that a general conceptual framework for analysis of the policy-making context in South Africa needs to be considered when analysing how to encourage science uptake in more specific cases. In this paper, the aim is to use the example of the National Freshwater Ecosystem Priority Areas (NFEPA) project to illustrate how to apply this framework and how research projects in South Africa can be better positioned for uptake.

\section{The case study}

The NFEPA project is an important national-level initiative as it offers concrete tools to improve and facilitate freshwater conservation management and planning in different sectors. This is especially relevant considering the dire state of South Africa's freshwater ecosystems (Roux et al., 2008).
The project is based on a high level of technical inputs and endorsement by scientific experts from a range of organisations, and aims to identify a national network of freshwater ecosystem priority areas. The NFEPA products include a set of digital maps of the priority areas at the national and water management area (WMA) level, a NFEPA atlas aimed at creating awareness among the end-user community and a more generalist audience, and an implementation manual targeting government actors in different sectors.

An additional aim of the project is for its products to be taken up into existing legislative tools and policy to enable resource managers to more easily do their work, and to be able to advise strategic managers on the protection of South Africa's freshwater ecosystems. In South Africa, the water and environmental government departments operate at various levels of scale. With water declared as a national competence in the South African Constitution (RSA, 1996), the Department of Water Affairs (DWA) has a national government department with regional offices as well as catchment management agencies (CMAs) (RSA, 1998a) at different stages of development. Environmental matters are declared as a provincial competence in the Constitution (RSA, 1996) and so the Department of Environmental Affairs (DEA) has a national department with relatively independent provincial departments (RSA, 1998b). In the national departments, the strategic managers (director-generals and deputy directorgenerals) have the power to make important strategic decisions. These people act on recommendations coming from resource managers, technical experts involved in the operational matters of the departments, who can be highly influential in advocating for certain policy recommendations to be adopted. Important decisions are also made by officials in strategic positions at the provincial level.

The NFEPA project is therefore a significant departure from the 'business as usual' paradigm as the project team has consistently grappled with issues of transdisciplinarity. This is most apparent in the diversity of experts who were involved in producing the research as well as in the way that the end users of the research, from both government and non-governmental sectors, were included in the research process from the problem definition phase to the completion of the project (Pohl, 2008; Reyers, 2010). 


\section{Positioning science projects in the South Africa policy-making context}

Public policy-making takes place in a specific socio-political context. Its direction is shaped by multiple and different actors, both official policy-makers and non-government actors, who interact in a complex political landscape (Cloete and Meyer, 2006), which is characterised by dynamic processes. In any policy-making process the inputs of a variety of official, intermediary and non-government actors is critical. The policy that is adopted (e.g. the national water policy and accompanying suite of legislation) comes about as a result of a series of debates, compromises and competition between this array of actors (Nienaber et al., 2010). Essentially, coalitions of actors are made up of a variety of official and non-government actors who advocate and defend a particular point of view (Van Buuren and Edelenbos, 2004). Once a policy has been developed and adopted, implementation needs to occur. Official policy-makers, and more specifically government departments, are responsible for implementation (Anderson, 2006).

This paper focuses on how the NFEPA project team has attempted to influence official policy-makers, and administration agencies in particular. This focus has arisen because the project itself placed particular emphasis on providing supportive tools to help with the implementation of existing environmental and water-related policy, for which government is finally responsible. Naturally, there are many other actors (see Fig. 1) who also need to be aware of and influenced by research. Whilst these actors are beyond the scope of this paper, many of the mechanisms used for influencing government are also relevant to the way that other actors (businesses, non-governmental organisations, interest groups, etc.) must be made aware of and included in research.

\section{Official policy-makers}

South Africa's official policy-making authority is the Government, which is made up of national, provincial and local spheres. The executive, legislature and judiciary form the 3 branches of Government and are mandated by the Constitution of South Africa to keep each other's powers in check (Anderson, 2006; SA Yearbook, 2008/9; Funke et al., 2011). The administrative agencies operate under the leadership of the executive and are responsible for carrying out the decisions (laws and policies) that are made in Parliament (Venter and Theunissen, 2006).

The executive, legislature, judiciary and administrative agencies (illustrated in Fig. 1) all have a specific role to play in policy debates, development and implementation in South Africa. The executive branch of Government, which is made up of the President, the cabinet, the provincial executive authority and municipalities (RSA, 1996), is a key player in setting the policy agenda, initiating policy debates, and, through the public service, implementing policy.

Similarly, Parliament at national and provincial level in South Africa plays an important part in the policy-making process, as bills are introduced here by the executive or initiated by Parliament itself (Joint Task Team on the Legislative Process in Parliament, 2010). Parliamentary portfolio committees, the 'watch dogs' of Parliament, debate proposed legislation and other issues (Taljaard and Venter, 2006). At the provincial level, it is the provincial legislature that has the power to pass provincial legislation (RSA, 1996). It is, ultimately, approved legislation that gives policy direction, clout and enforceability.
The judiciary, and, in the last instance, the Constitutional Court, play a role in policy through review of legislation and executive decisions, and declare decisions invalid if they are judged to be unconstitutional (Mathisen and Tjonneland, 2001; SA Yearbook, 2008/9).

\section{Non-official policy-makers (civil society)}

Civil society differs from official policy-makers because it does not have 'legal authority to make binding policy decisions', nor is it finally responsible for implementing policy, but may provide a supporting role to implementation by persuading, exerting pressure and providing information (Anderson, 2006). A number of different actors in civil society have the power to influence the policy-making process, including policy implementation.

Civil society includes interest groups, who aim to promote their interests in society and lobby the government to respond to them (Sadie 2006; Lehman, 2008), and political parties, who help to articulate policy needs and the demands of their supporters. Given the dominant party system in South Africa, however, opposition parties have limited power to influence policy debates (Taljaard and Venter, 2006).

Research organisations, which come in a variety of forms and structures, influence policy by articulating needs, developing solutions, making recommendations, advising decisionmakers, supporting implementation, etc. (Strydom et al., 2010). However, scientific evidence can take too long to produce to be able to meet the short-term demands of policy-makers. It may also not be presented in a digestible format. These factors, and the poor levels of engagement between scientists and policymakers (Gilson and McIntyre, 2008; Strydom et al., 2010), can limit the impact of science on policy.

The media is also an important influence on policy as it can impact on public and political opinion and therefore on shaping the policy agenda. This is because the media are capable of both indoctrinating and educating millions of people on policy issues in order to rally support for specific issues (Zegeye and Harris, 2002; Cloete and Meyer, 2006).

In addition, since 1994, a number of laws have been passed which give individuals the right to engage in the affairs of authorities, especially at the local level (Williams, 2004). Thus, through a variety of channels, such as mass action, civic, cultural and religious organisations, individuals can influence policy debates.

Another critical non-government actor which has direct and indirect influence on policy is the business sector. The South African Government and the business sector have a complex relationship. The business sector, which represents a multitude of interests and roles, requires an enabling environment, fostered by appropriate government policies, to be successful. The government in turn requires funding and resources to function effectively, and relies on the business sector, which is a major contributor to the tax base. In addition, the institutionalisation of South Africa's business sector as a role player in the policy process, through the National Economic Development and Labour Council (NEDLAC), emphasises and entrenches the importance of the business sector in this context (NEDLAC, 2010; Funke et al., 2011).

\section{Bridging actors}

This actor cluster reserves a space for those actors that do not neatly fit into the official or non-government category. There 
is a large variety of different actors that fall into this space. The common characteristic of these actors is that they are not completely independent of government, but rather act as a 'gobetween' actor mediating and/or supporting communication between government and other actors in society (ENCYCLO, 2010). These actors include intermediary organisations that channel inputs between non-government actors and official policy-makers, and knowledge brokers that help with the interpretation of science to policy-makers.

Now that the South African policy-making context within which science uptake can take place has been discussed, it becomes important to apply this framework to the specific contexts of different research projects to determine how they can be better positioned for science uptake. In the case of the NFEPA project, this means focusing on the role of bridging actors and the context within which government departments (see right hand side of Fig. 1) function. Specifically, this paper analyses the challenges faced by resource managers in their day-to-day work, as well as how these impact their ability to make use of new scientific research products, such as those produced by the NFEPA project, that have been designed to support their work. Understanding the context within which end-users of scientific research products operate is important as it can help scientists to better tailor their products and strategies to promote successful science uptake.

\section{Applying the framework to specific science projects: the case of NFEPA}

Figure 1 gives a generic depiction of the socio-political context of actors that can potentially be involved in policy debates. In order to have a truly integrated, holistic and transdisciplinary response to a given policy problem, a variety of all of the abovediscussed actors needs to be involved in the problem definition, policy development, and implementation. Each specific policy debate has its own unique set of actors and emphases to take into account. This section applies the policy-making framework to the NFEPA project to illustrate how it is situated for science uptake in policy implementation.

Occupying an important place in the policy-making framework, bridging actors play a variety of roles in facilitating science uptake by other actors in the policy implementation process. These actors are important when facilitating uptake, given that they tend to have closer ties and institutional relationships with government than most non-government actors, who are often not privy to the details of government processes, hierarchy and functioning.

The South African National Biodiversity Institute (SANBI) is the main bridging actor that has been involved in the NFEPA project. SANBI is a public entity that was established in terms of the National Environmental Management: Biodiversity Act of 2004 (RSA, 2004) and falls under the Department of Environmental Affairs (DEA) (Driver, 2010). One of the functions of SANBI's biodiversity policy directorate (under its knowledge, policy and network management branch) is to ensure that biodiversity science influences policy, management and decision-making (SANBI, 2010). SANBI is part of government and therefore has relatively easy access to people at decisionmaking levels in the Department of Water Affairs (DWA) and DEA, more so than research institutions and other actors who are 'outsiders' to the government structure (Driver, 2010). Having a bridging actor such as SANBI as part of the project team has created the opportunity for greater uptake of the NFEPA products by the administrative agencies and a bigger opportunity for endorsement of the project by relevant members of the executive. In addition to bridging actor involvement in facilitating science uptake, a variety of non-government actors needs to be part of the process, as illustrated in Fig. 1. Soliciting inputs from a diverse set of actors increases the level of quality and credibility of the scientific research products because of the benefits of combining diverse experiences and expertise when different actors work together.

The NFEPA project team has consulted a variety of nongovernment actors when working on the NFEPA products by inviting them to numerous stakeholder feedback meetings and expert review workshops between August 2008 and March 2011 (the time-frame of the project). The project team also attended existing forums, and initiatives (e.g. the National Wetlands Indaba and the Biodiversity Planning Forum). Inputs to the products have come from non-governmental organisations (NGOs), universities, industry, consultants, research councils and museums. While it may be argued that more non-government actors could have been consulted and that this might have further promoted science uptake, numbers had to be limited for practical reasons. Also, not everyone who was invited to participate ended up attending.

Official policy-makers are the third important actor whose involvement is necessary to increase a research project's potential for science uptake, especially at the government or policy level. Involving government actors can lead to greater awareness and buy-in of scientific research products, and can assist with inputs into product design. It is important to ensure government actors' support for scientific research products, as they will be the ones using them on a day-to-day basis and will need the products to complement the legislative tools and policy (e.g. the water resource classification process) which they are already working with.

Government consists of a diverse set of actors and structures and therefore needs to be engaged at the most relevant and appropriate levels to facilitate the uptake and use of scientific research products. For the NFEPA project, the project team primarily consulted DWA and DEA at the national and provincial level. The Breede-Overberg and Inkomati Catchment Management Agencies (CMAs) were also consulted. For the most part, the team consulted the resource management base of the departments (who were also invited to the stakeholder feedback meetings and expert review workshops), and to a lesser extent the strategic managers. This may have been because it was more difficult and took more effort to meet with government officials at the strategic level than at the resource management level. Also, the development of the NFEPA products had to be quite advanced before the NFEPA project could be effectively introduced and marketed to strategic managers. Examples of this kind of interaction include a NFEPA project team with SANBI, DWA and DEA, and a presentation at DEA's Ministerial Technical Committee (MINTEC), a structure set up to facilitate coordination between national DEA and provincial environmental departments (SOER, 2011).

Given the above discussion, it is clear that the NFEPA project has actively sought to be transdisicplinary and inclusive in the way it has gone about trying to solve the problems facing freshwater biodiversity in South Africa. It has engaged and included a diverse set of actors with differing viewpoints, values, knowledge and understandings of the world.

\section{Method}

In order to establish some of the challenges that the resource managers who work in administrative agencies face in their 
day-to-day work, the authors conducted semi-structured interviews with 16 resource managers who were involved in the expert review process of the NFEPA products. These individuals mostly have a technical background and work for the national and provincial water and environmental departments. The authors conducted semi-structured interviews with the respondents in order to establish their roles and responsibilities within the larger organisation they work for, the extent to which they focus on conservation in their day-to-day work, the challenges that they face and whether they would find the NFEPA products useful and have any recommendations for the NFEPA project team to ensure that the products will be taken up and used.

Semi-structured interviews were chosen as a research method because they are useful when respondents cannot be directly observed over a long period of time (Punch, 1998). Such interviews also allow the interviewer to keep the focus on the topic of the interview, while the respondent is able to direct its content, because they are providing information which they feel is important (Creswell, 1994). Establishing how to make the NFEPA products relevant to their intended end-users is imperative for making recommendations on improving their potential for successful science uptake.

\section{Challenges affecting science uptake}

Given its transdisciplinary approach, the NFEPA project has been planned for impact from the beginning. A wide variety of actors has been consulted and involved during the process of developing the NFEPA products. However, consultation and involvement are no guarantee that the products will be used in the end. It is therefore important to understand the daily challenges that resource managers, one of the potential end-users of the NFEPA products, face as this is likely to impact on their capacity to effectively use them in their day-to- day work, to 'market' them to others and to advise strategic managers.

From the interviews conducted, it has become apparent that 3 main issues seem likely to impact on the uptake of the NFEPA products by government and any other scientific research products that promote conservation objectives. Unless referenced otherwise, the following recommendations are based directly on suggestions made by those interviewed.

\section{Government priorities}

The first emergent issue is that of government priorities. Governments are constantly under pressure to meet multiple needs and demands and tend to prioritise certain issues over others. The South African Government, in particular, tends to prioritise development (e.g. water service delivery, mining and tourism) over conservation. This means that strategic priorities and choices do not always emphasise the environment and reflects Government's inability to effectively balance short-term needs with long-term realities. With conservation not being fully prioritised, it is difficult for resource managers to promote a balance between conservation and development when advising their strategic managers.

\section{Compliance with national legislation}

The second emergent issue refers to compliance with national legislation. While good legislation exists to manage the environment and other sectors, compliance with this legislation is often not rigorously enforced and monitored. For example, in terms of the environment, there appears to be a break-down of communication between industry and government. Industry actors, such as mining companies and developers, often do not understand the role of government in regulating their sector, and are unable to communicate the required information clearly. Also, the turn-around time to take decisions between different government departments regarding development is very slow. A related challenge is that of enforcing the national environmental legislation. Several of the respondents stated that some developers would prefer to pay a fine, rather than follow the required environmental authorisation process.

A context where existing legislation is not enforced might prohibit scientific research products from having the desired impact. In the case of the NFEPA project, which aims to support and feed into the existing legislative tools and policy, this challenge can be an impediment to uptake.

\section{Capacity challenges in government departments}

The third emergent issue is that of capacity challenges within South African government departments, which make it difficult for government employees to carry out their day-to-day operations. Many of the government departments and sub-units interviewed are understaffed, which means that the employees have very heavy workloads. Also, there is a lack of highly qualified and experienced individuals as many employees are employed with limited experience and often do not have a scientific background. There is also a problem of high staff turn-over and absence of succession training as new staff are often not mentored and trained sufficiently by existing employees, who either retire or move on to other jobs, particularly in the higher-paying private sector.

The biodiversity sector is attempting to address this problem through its Human Capital for Biodiversity Initiative, which aims to establish a 'socially equitable and suitably skilled workforce of biodiversity leaders, professionals and technicians to optimally implement the biodiversity sector's expanding, dynamic and increasingly complex mandate.' More specifically, its goals are linked to transformation in the biodiversity sector, skills development and the retention and suitable deployment of individuals in the sector, as well as creating attractive conditions for skills planning, development and evaluation (Human Capital Development for Biodiversity, 2011). Such a human capacity development initiative is also necessary when it comes to water management and conservation as this sector is also very short of staff.

There are also bureaucratic problems around complicated intra-departmental processes, which include a lack of communication between chief directorates, inaccessibility of information, an overload of rules and regulations and a lack of funding in certain areas. These issues limit the capacity of government employees to absorb and use new scientific research products and tools, given the already stressful work environment they have to function in.

\section{Recommendations to improve science uptake}

The understanding of the resource managers' context and challenges, as discussed above, and additional interview questions that were asked about how to improve the relevance and use of the NFEPA products, enable the authors to suggest how the impact of the NFEPA project can possibly be increased. In addition, these findings can be generalised and made relevant to improve the uptake of other scientific research products in South Africa. 


\section{The 'who' and 'how' of targeting government departments}

The first recommendation involves the issue of targeting potential end-users within government with the NFEPA products. This implies that relevant end-users need to be actively sought out, contacted and informed about the products as it cannot be assumed that these products will automatically 'filter' through to all relevant actors (Funke et al., 2011). In addition, social learning (Hoppe, 1999) and transdisciplinary literature (MaxNeef, 2005) strongly advocate that this 'targeting' needs to occur throughout the research process. If government departments are involved in the definition of the research problem and are regularly consulted throughout the research process, trust and awareness of the scientific research products is encouraged.

The interview process has revealed that an ideal targeting situation has 4 components. Firstly, all levels of government (national, provincial and local) need to be made aware of the products. Ideally this requires making personal contact with relevant departments. However, given the practical challenges of time and access that this requirement poses, it is important to be innovative in how these departments are accessed (Funke et al., 2011).

Secondly, various levels of the political hierarchy within each of the abovementioned tiers need to be targeted. Thus it is important for both the strategic managers and their advisors (resource managers) to be aware of the products. Here it is important to target leaders who think strategically and are enthusiastic enough to mobilise others into action.

Thirdly, a wide range of government departments should be targeted. Therefore, it is not enough to simply target the most directly involved government departments (in this case DWA and DEA) but also to target other departments that affect or are impacted by conservation efforts. The NFEPA project team has realised the need for wider interaction and is planning to engage the mining and agriculture sectors to a greater extent in future.

Fourthly, it needs to be recognised that government departments do not operate in isolation but are often supported and their activities scrutinised by a range of actors. These actors are not necessarily part of government. They generally fall in the non-government or civil society group (Nienaber et al., 2010) and include consultants, research organisations, academic institutions, major donor partners and bridging actors. Given the supportive role that such actors play in implementation, they also need to be made aware of research. Although a detailed analysis of these actors falls beyond the scope of this paper it is important to note that the NFEPA project did involve a variety of these other actors both within the research team and in a more consultative or advisory manner.

There are numerous ways to go about targeting government departments. Firstly, targeting requires that there is a plan of action in place that is regularly followed up on (Nienaber et al., 2010). Such a plan, which will be project specific, needs to be designed to inform government departments, steer them into action and follow up on them when necessary.

Secondly, the manner in which end-users in government are informed about scientific research products is important. Here it is crucial not to be patronising when promoting, explaining or distributing the products, but rather to create an 'exchange between equals' when sharing information about the products and taking into account the day-to-day challenges of the person one interacts with.

Thirdly, targeting should be streamlined by tapping into existing networks, such as management meetings and seminars, for the distribution of new scientific research products (Strydom et al., 2010). Also, a variety of media should be used to disseminate and generate awareness about scientific research products. This could include brochures and websites aimed at laypersons, a clip on an environment-focused television documentary such as 50/50, articles in environmental newsletters and policy briefs (Strydom et al., 2010).

From the interviews with the resource managers, it appears that there are differing views about what the most appropriate paradigm for dissemination is. Some advocate a top-down dissemination approach suggesting that without a mandate from the top levels of government (in this case the strategic managers of the relevant departments) the products are unlikely to be appropriately endorsed, disseminated and utilised. Others promote a bottom-up approach, suggesting that it is best to target provinces and/or the advisors in the various departments as it is these actors who advise strategic managers in the provincial and national departments about the most appropriate decisions to make. Here it is also argued that the message 'gets lost' if one takes a top-down approach as communication is not always effective between senior and junior staff members and between national, provincial and local government. Another suggestion takes the form of a hybrid approach that combines these 2 points of view. Gauging from the mixed opinions about the top-down versus bottom-up options, it makes sense for project teams to adopt both strategies where relevant.

\section{Packaging and communicating the product}

The second recommendation explores how to make scientific research products something that government departments can understand and use in an efficient and user-friendly manner. Packaging and communication of a scientific research product needs to be underpinned by some degree of marketing or entrepreneurial logic (Gilson and McIntyre, 2008). Therefore, scientific research products need to illustrate that they fill a strategic gap or opportunity in society (Johnson et al., 2008). The entrepreneurial logic refers to what product the end-user wants, needs and trusts, how it should be packaged and what support systems an end-user requires to continue using the product in the long-run.

To elaborate further, end-users of science in government want scientific research products to improve their ability to 'do' their work effectively. This can be achieved if the products fit into existing legislative tools and policy as has been the case with the NFEPA products. It is also important that scientific research products are timely. Busy government employees are unlikely to 're-do' work that has already been done even if this may lead to a better result, nor are they likely to produce work that is based on science that is too 'new' for fear that the work may be rejected.

In order for end-users in government to use scientific research products these need to be perceived as credible (Strydom et al., 2010), and the quality, standard and reliability of the product need to be trusted. This can be achieved in many ways. Firstly, the project team has to be made up of a multidisciplinary group of experts. Secondly, the project team must consult widely with other experts in the field, from a range of institutions, particularly those working in the area of implementation. This adds to the quality of the scientific research products and also encourages greater word-of-mouth awareness about them, which is an important source of trust-building. Thirdly, if there is open endorsement of the products by leading stakeholders in relevant sectors, the perception of trust around 
the products is increased. In the case of NFEPA, SANBI, DWA, DEA, the World Wide Fund for Nature (WWF) and the Council for Scientific and Industrial Research (CSIR) all endorsed the products, which facilitated confidence and trust in the products.

The packaging of the scientific research products is another critical ingredient when trying to encourage effective uptake. If products are not presented in a way that is appealing, digestible and relevant to government departments, they are unlikely to be used, regardless of the quality or importance of the product. To ascertain these preferences, end-users need to advise the project team on how they would want specific scientific research products to be packaged (Johnson et al., 2008; Strydom et al., 2010). In the case of NFEPA, a long list of recommendations emerged from the engagement around packaging. This included practical suggestions around the importance of having web-based and hard copies of the products, and more conceptual suggestions about the importance of striking a balance between detail and simplicity.

Finally, when trying to sell a product it is important to provide government departments with the ongoing support that they may need to use the products most effectively and easily. Again, in this regard it is necessary to consult with end-users (Johnson et al., 2008; Strydom et al., 2010). The NFEPA interaction around necessary support structures produced a variety of suggestions. Firstly, there is a need for workshops to explain how to use and apply the NFEPA products. Such workshops cannot be once-off as they need to target multiple audiences and respond to the reality of high staff turnover rates. Secondly, there is a need for a 'go to' person, call line, or office so that queries can be made and questions can be asked. Thirdly, supporting documentation is also necessary. Finally, it is important to have updated versions of the products in order to keep the science that is supporting government strategies and plans current and relevant.

\section{Grappling with the politics in science dissemination}

The third recommendation involves grappling with and recognising politics and political processes when trying to disseminate scientific findings and products. In almost all of the interviews that were conducted, it was suggested that it is critical to engage with the political leadership of the government departments. This engagement is important as it is ultimately these actors that make the final decisions in these departments.

Theoretically, the strategic managers are guided by the recommendations of the resource managers in the government departments. This suggests that if the resource managers know about the products and use them to feed into recommendations, the NFEPA products should be heard and used by management in decision-making. However, in reality, strategic managers are juggling multiple inputs at once and are therefore also influenced by broader political priorities, agendas and trends. Factors such as personal trust relationships and the effectiveness of departmental communication channels also play a large role in shaping decisions (Nienaber et al., 2010; Strydom et al., 2010; Funke et al., 2011). Other complicating factors are that high-level strategic managers in South Africa seldom have technical or scientific expertise and thus will find it harder to understand the subtleties and details of projects like NFEPA. These individuals are also often very difficult to contact as they are very busy.

A number of practical suggestions have been offered by the respondents to overcome this challenge in South African government departments. Firstly, there are a few individuals in most departments who have the 'ear of the politicians'. They are trusted and can convey information in a way that is digestible to strategic managers, thereby increasing the likelihood of these people becoming enthusiastic about scientific research products, e.g. NFEPA. A good forum for bringing together scientists and political actors is at government departments' management meetings.

Thirdly, it is important to understand the mind of strategic managers, who need to make decisions and take actions that have political mileage. This means that products need to suit the political climate in which they work, present politicallycorrect or appropriate solutions, and be accessible enough for strategic managers to take ownership of them.

Fourthly, a bridging actor, such as SANBI in the case of the NFEPA products, can be used to access strategic managers via Parliamentary briefs, personal meetings, etc. Strategic managers are expected to make time to communicate with SANBI, because it forms part of government, which means that this could be an effective science communication channel for NFEPA and other scientific research products.

\section{Conclusion}

This paper has suggested that in order to establish how to promote better science it is necessary to understand the policymaking context. This implies that it is necessary for project teams to engage multiple actors when working on scientific research products in order to generate awareness about these products and to enhance their legitimacy. It is also particularly important to consult with end-users in government in an ongoing manner throughout the duration of a project as this will ensure that the end product is relevant and useful to those who are responsible for implementation. Similarly, it is important to be aware of the individual contexts of end-users in government in order to tailor the scientific research products in a way that ideally suits the end-users' specific needs and challenges. This way of understanding science uptake is about moving away from linear information transfer strategies towards seeing science as something that is produced and taken up through an inclusive and interactive process that plays out amidst a complex web of actors and issues.

In the case of the NFEPA project, this has meant understanding the daily context and challenges that the potential end-users of the research in government are facing. Challenges include government prioritising development over conservation, lack of compliance with national legislation (which hampers the uptake of scientific research products) and capacity problems in government departments. From this understanding, and additional interview questions that were asked about how to improve the relevance and use of the NFEPA products, the authors have made some suggestions about how the impact for this project can possibly be increased. Findings include knowing 'who' to target and 'how', the importance of packaging and communicating scientific research products, and the need to deal with the politics of research dissemination. These findings are not only relevant to the NFEPA project, but are also relevant to improving the uptake and use of other scientific research products in South Africa.

Given the importance of understanding the policy-making context in order to ensure effective science uptake, the authors propose that the policy-making framework, as discussed and applied in this paper, could also be applied to the contexts of other research projects to determine how they too can be better positioned for science uptake. 


\section{References}

ANDERSON JE (2006) Public Policymaking. Houghton Mifflin Company, Boston. 331 pp.

ARLETTAZ R, SCHAUB M, FOURNIER J, REICHLIN TS, SIERRO A, WATSON JEM and BRAUNISCH V (2010) From publications to public actions: when conservation biologists bridge the gap between research and implementation. BioScience 60 (10) 835-842.

BOREUX V, BORN J and LAWES MJ (2009) Sharing ecological knowledge: opportunities and barriers to uptake. Biotropica 41 (5) 534-534.

BOWEN S and ZWI AB (2005) Pathways to "evidence-informed" policy and practice: A framework for action. PLoS Med 2 (7) e166. doi:10.1371/journal.pmed.0020166.

CAMPBELL S, BENITA S, COATES E, DAVIES P and PENN G (2007) Analysis for Policy: Evidence-Based Policy in Practice. Government Social Research Unit, London. 40 pp.

CLOETE F and MEYER IH (2006) Policy agenda setting. In: Cloete F, Wissink $\mathrm{H}$ and De Coning C (eds) Improving Public Policy from Theory to Practice. Van Schaik Publishers, Pretoria. 105-123.

CRESWELL JW (1994) Research Design: Qualitative and Quantitative Approaches. Sage Publications, Thousand Oaks, London, New Delhi. 228 pp.

COWLING RM, EGOH B, KNIGHT AT, O'FARRELL PJ, REYERS B, ROUGET M, ROUX DJ, WELZ A and WILHELM-RECHMAN A (2008) An operational model for mainstreaming ecosystem services for implementation. PNAS 105 (28) 9483-9488.

DEAT (DEPARTMENT OF ENVIRONMENTAL AFFAIRS AND TOURISM, SOUTH AFRICA) (2011) State of the Environment Report. URL: http://soer.deat.gov.za/131.html (Accessed 17 February 2011)

DRIVER M (2010) Personal communication, 3 September 2010, at SANBI offices, Kirstenbosch Botanical Gardens, Cape Town. Director Biodiversity Policy, SANBI, Private Bag x7, Claremont, 7735\.

ENCYCLO (2010) ENCYCLO Online Encyclopaedia. URL: http:// www.encyclo.co.uk/define/intermediary (Accessed 18 February 2011).

FUNKE N, NIENABER S and HENWOOD R (2011) Scientists as lobbyists? How science can make its voice heard in the South African policy-making arena? J. Public Affairs 11 287-296. doi: 10.1002/pa.421.

GIBBONS P, ZAMMIT C, YOUNGENTOB K, POSSINGHAM HP, LINDENMAYER DB, BEKESSY S, BURGMAN M, COLYVAN M, CONSIDINE M, FELTON A, HOBBS RJ, HURLEY K, McALPINE C, McCARTHY MA, MOORE J, ROBINSON D, SALT D and WINTLE B (2008) Some practical suggestions for improving engagement between researchers and policy-makers in natural resource management. Ecol. Manage. Restoration 9 (3) 182-186.

GILSON L and MCINTYRE D (2008) The interface between research and policy: experience from South Africa. Soc. Sci. Med. 67 748-759.

HANNEY SR, GONZALEZ-BLOCK MA, BUXTON MA and KOGAN M (2003) The utilisation of health research in policymaking: concepts, examples and methods of assessment. Health Res. Pol. Syst. 1 2. doi:10.1186/1478-4505-1-2.

HEYWOOD A (2002) Politics. Palgrave Foundation, New York. 416 pp.

HOPPE R (1999) Policy analysis, science and politics: from 'speaking truth to power' to 'making sense together'. Sci. Public Pol. 26 (3) 201-210.

HUMAN CAPITAL DEVELOPMENT FOR BIODIVERSITY (2011) URL: http://www.skillsforbiodiversity.org.za (Accessed 17 February 2011).

JOHNSON G, SCHOLES K and WHITTINGTON R (2008) Exploring Corporate Strategy: Text and Cases. Prentice Hall, Financial Times Press, New Jersey. 878 pp.

JOINT TASK TEAM ON THE LEGISLATIVE PROCESS IN PARLIAMENT (2010) Parliament of the Republic of South Africa Website. URL: www.parliament.co.za (Accessed 14 May 2010).

KNIGHT AT, DRIVER A, COWLING RM, MAZE K, DESMET PG, LOMBARD AT, ROUGET M, BOTHA MA, BOSHOFF AF,
CASTLEY JG, GOODMAN PS, MACKINNON K, PIERCE SM, SIMS-CASTLEY R, STEWART WI and VON HASE A (2006) Designing systematic conservation assessments that promote effective implementation: best practice from South Africa. Cons. Biol. 20 (3) 739-750.

KNIGHT AT, COWLING RM, ROUGET M, BALMFORD A, LOMBARD AT and CAMPBELL BM (2008) Knowing but not doing: selecting priority conservation areas and the researchimplementation gap. Cons. Biol. 22 (3) 610-617.

LEHMAN H (2008) The emergence of civil society organisations in South Africa. J. Public Affairs 8 115-127.

MATHISEN HW and TJONNELAND EN (2001) Does Parliament matter in new democracies? The case of South Africa 1994-2000. WP 2001:1. Chr. Michelsen Institute, Development Studies and Human Rights, Bergen. 13 pp.

MAX-NEEF MA (2005) Commentary: foundations of transdisciplinarity. Ecol. Econ. 53 5-16.

McNIE E (2007) Reconciling the supply of scientific information with user demands: an analysis of the problem and review of the literature. Environ. Sci. Pol. 10 17-38.

MUBYASI GM and GONZALEZ-BLOCK MA (2005) Research influence on anti-malarial drug policy change in Tanzania: case study of replacing chloroquine with sulfadoxine-pyrimethamine as the first-line drug. Malaria J. 451.

NATIONAL ECONOMIC DEVELOPMENT AND LABOUR COUNCIL WEBSITE (2010) URL: www.nedlac.org.za (Accessed 14 May 2010).

NIENABER S, FUNKE N, NORTJE K and STRYDOM WF (2010) A reality check about evidence-based policy-making: the case of male circumcision as an emerging policy intervention for HIV/ AIDS. CSIR Parliamentary Grant Report CSIR/NRE/WR/ EXP/2011/0017/A. CSIR, Pretoria. 30 pp.

PIERCE SM, COWLING RM, KNIGHT AT, LOMBARD AT, ROUGET M and WOLF T (2005) Systematic conservation planning products for land-use planning: interpretation for implementation. Biol. Cons. 125 441-458.

POHL C (2008) From science to policy through transdisciplinary research. Environ. Sci. Pol. 11 46-53.

PULLIN AS, KNIGHT TM, STONE DA, CHARMAN K (2004) Do conservation managers use scientific evidence to support their decision-making? Biol. Cons. 119 245-252.

PUNCH KF (1998) Introduction to social research: quantitative and qualitative approaches. Sage Publications, London, Thousand Oaks, New Delhi. 336 pp.

REYERS B, ROUX DJ, COWLING RM, GINSBURG AE, NEL JL and O'FARRELL PO (2010) Conservation planning as a transdisciplinary process. Cons. Biol. 24 (4) 957-965.

RSA (1996) Constitution of South Africa. Act No. 108 of 1996. Government of South Africa, Pretoria. 107 pp.

RSA (1998a) National Water Act. Act No.36 of 1998. Department of Water Affairs and Forestry, Pretoria. 94 pp.

RSA (1998b) Environmental Management Act. Act No. 107 of 1998 Department of Environmental Affairs and Tourism, Pretoria. 37 pp.

RSA (2004) National Environmental Management: Biodiversity Act. Act No. 10 of 2004. Department of Environmental Affairs and Tourism, Pretoria.

ROUX DJ, ROGERS KH, BIGGS HC, ASHTON PJ and SERGEANT A (2006) Ecol. Soc. 11 (1) 4.

ROUX DJ, ASHTON PJ, NEL JL and MACKAY HM (2008) Improving cross-sector policy integration and cooperation in support of freshwater conservation. Cons. Biol. 22 1382-1387.

SADIE Y (2006) Political parties, interest groups and social movements. In: Venter A and Lansberg C (eds). Government and Politics in the New South Africa. Van Schaik Publishers, Pretoria. 202-229.

SHACKLETON CM, CUNDILL G and KNIGHT AT (2009) Beyond just research: experiences from Southern Africa in developing social learning partnerships for resource conservation initiatives. Biotropica 41 (5) 563-570.

SHISANA O and LOUW J (2006) Translating research into policy: the case of orphans and vulnerable children in South Africa. J. Soc. Aspects HIV/AIDS 3 450-456. 
SHUNG-KING M (2006) The ebb and flow of child health policy development in South Africa: three case studies reflecting the role of the Children's Institute at the University of Cape Town in shaping child health policy in South Africa. Children's Institute, University of Cape Town, Cape Town. 40 pp.

SOUTH AFRICAN NATIONAL BIODIVERSITY INSTITUTE (2010) About the governance structure of SANBI. URL: www.sanbi. org (Accessed 6 January 2011).

SOUTH AFRICAN YEARBOOK (2008/9) Government Communications Website. URL: http://www.gcis.gov.za/resource centre/ sa info/yearbook/index.html (Accessed 14 May 2010).

STRYDOM W, FUNKE N, NIENABER S, NORTJE K and STEYN M (2010) Evidence-based policy-making: a review. S. Afr. J. Sci. 106 (5/6) 1-9.

TALJAARD R and VENTER A (2006) Parliament. In: Venter A and Lansberg C (eds). Government and Politics in the New South Africa. Van Schaik -Publishers, Pretoria. 17-37.
VAN BUUREN A and EDELENBOS J (2004) Conflicting knowledge: Why is joint knowledge production such a problem? Sci. Public Pol. 31 (4) 289-299.

VAN KERKHOFF L and LEBEL L (2006) Linking knowledge and action for sustainable development. Ann. Rev. Environ. Resourc. 31 445-477.

VENTER A and THEUNISSEN C (2006) Administering national government. In: Venter A and Lansberg C (eds.). Government and Politics in the New South Africa. Van Schaik Publishers, Pretoria. 81-93.

WATSON RT (2005) Turning science into policy: challenges and experiences from the science-policy interface. Phil. Trans. R. Soc.: Biol. Sci. 360 471-477.

WILLIAMS JJ (2004) Citizenship, community participation and social change: the case of area coordinating teams in Cape Town South Africa. Inst. Dev. Stud. Bull. 35 1-91.

ZEGEYE A and HARRIS R (2002) Media, identity and the public sphere in post-apartheid South Africa: an introduction. Asian Afr. Stud. 1 239-263. 
http://dx.doi.org/10.4314/wsa.v38i1.13 Available on website http://www.wrc.org.za

ISSN 0378-4738 (Print) = Water SA Vol. 38 No. 1 January 2012 ISSN 1816-7950 (On-line) = Water SA Vol. 38 No. 1 January 2012 